\section{Learning From Our Mistakes}

$I_{\text {no }}^{n}$ February, my thoughts generally turn to pleasantries like chocolates and flowers for Valentine's Day or our regular family ski trip over President's Day weekend. This year is very different. I am focused solely on when my husband will get his first COVID-19 vaccination. The fact that, as of writing, 2 vaccines have FDA approval and more are on the way is nothing short of miraculous. The increase in production by the industry giants responsible for these vaccines has also been a tour de force. Unfortunately, getting the vaccine into the arms of people has been more complicated. You would think that would be the easy part.

The plan for distribution of the vaccine has essentially been left up to individual states. Sure, the CDC provided guidance on priority order of who should be vaccinated, but getting the job done has been left to the states. In fact, in some states, this responsibility has been passed down to counties. Naturally, different states have different approaches. For instance, in Florida, vaccines were available even before New Year's Day to healthy ambulatory older subjects who queued up in lines, albeit sometimes for hours. At the same time in California, the manager of my 95 -year-old mother's assisted living facility had no idea when they might get the vaccine. This is despite the fact that residents in assisted living facilities were supposed to be in "tier 1" for distribution. Even within the tiers in California, some inequities seem to exist. For example, dentists and their staff were placed in tier 3 although tier 2 included public health field staff. Come on, have you ever had your teeth cleaned? Talk about an aerosol-producing procedure!

Disparities also occur within professions based on where someone works. If you work in a large integrated clinical system (such as the University of California San Francisco, where I practice), all patient-facing personnel were vaccinated by the end of January. That's because we had the staff available to set up vaccine clinics and a great plan for distribution. Therefore, physical therapists were protected early, but a private physical therapy group in the community needed to wait because they were tier 3. Further, a small community hospital fighting a COVID-19 surge may have limited capacity to launch a vaccine effort. Where do they get the help they need?

I may sound like I am being critical of these vaccine efforts, but I am not. I understand that this has never been done before. If I am critical of anything, it is the country's lack of a pandemic plan, but let's not go there. Further, I think this experience and these disparities in vaccine access will teach us for the future: we will learn what worked best to rein in this virus and we can adopt new standard operating procedures going forward.

As oncologists, we will, of course, keep a close eye on the outcomes in patients with cancer, especially those with immunosuppressive conditions like hematologic cancers. Right now, the California tier system for vaccination does not call out disease categories for special consideration. Should it? Sadly, we will need to wait to find out. But if this ever happens again, we should be better prepared. JNCCN@nccn.org or log into www.editorialmanager.com/JNCCN.

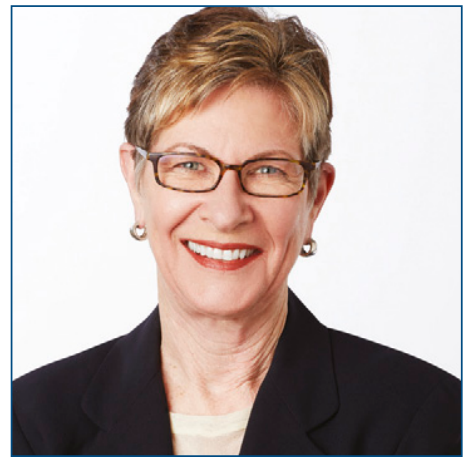

MARGARET TEMPERO, MD

Margaret Tempero, MD, is a Professor of Medicine and Director of the UCSF Pancreas Center and editor-in-chief of JNCCN. Her research career has focused on pancreatic ductal adenocarcinoma, especially in the area of investigational therapeutics. Dr. Tempero has served on the ASCO Board of Directors and as ASCO President. She currently serves on the ASCO Conquer Cancer Foundation Board. She codirected the AACR/ASCO Methods in Clinical Cancer Research and taught this course and similar courses in Europe and Australia. She was founding Chair of the $\mathrm{NCl}$ Clinical Oncology Study Section and served as a member and Chair of the $\mathrm{NCl}$ Board of Scientific Counselors Subcommittee A. She is a member of the Scientific Steering Committee and Chair of the Clinical and Translational Study Section for the Cancer Prevention \& Research Institute of Texas. She is or has been on the Scientific Advisory Boards of the Lustgarten Foundation, the Pancreatic Cancer Action Network, the V Foundation, The Alberta Canada Cancer Board, and the EORTC. She served as a member of the Oncology Drug Advisory Committee for the FDA. She has served as Deputy Director and Interim Director for the UNMC Eppley Cancer Center. She is Chief Emeritus of the Division of Medical Oncology at UCSF. She served as the founding Deputy Director and was later Director of Research Programs at the UCSF Helen Diller Family Comprehensive Cancer Center.

doi: 10.6004/jnccn.2021.0009

The ideas and viewpoints expressed in this editorial are those of the author and do not necessarily represent any policy, position, or program of NCCN. 